\title{
A Study to Determine the Correlation between the Intercondylar and Interdental Widths in South Indian Population: A Cross-sectional Study
}

\author{
Athma Shetty ${ }^{1}$, Manali Oswal ${ }^{2}$, Manoj Shetty ${ }^{3}$, Omkar Shetty $^{4}$, Nivya John ${ }^{5}$, Naresh Shetty ${ }^{6}$
}

\begin{abstract}
Aim: Anatomical landmarks that remain fairly constant throughout an individual's life help determine the position of the artificial teeth closer to that of their predecessors. The aim of the present study was to evaluate whether there is a relationship between the intercondylar widths (ICWs) and the interdental widths (IDWs) in the maxillary and mandibular arches in dentate subjects.

Materials and methods: The study was conducted in two parts, with 80 dentate subjects in total. Initially, in the first 40 subjects, a mathematical index was obtained by dividing the mean ICWs by the mean IDWs. In the second part, the ICW was measured and was used along with the index obtained in the first part, to estimate the IDW. These estimated values were then verified with the real IDWs by direct intraoral measurements. An arbitrary earpiece facebow (ARTEX ${ }^{\circledR}$ Gesichtsbogen Facebow) was used to measure the ICW. Statistics was done using SPSS software version 18 using Karl Pearson's correlation test and paired $t$-test.

Results: The IDW was correlated to the ICW; the maximal correlation was found between ICW and lower 6-6 width (L6-6W) ( $p$ value 0.033) and the lowest correlation was found between ICW and upper 6-6 width (U6-6W) ( $p$ value 0.046).

Conclusion: ICW can be used as an additional guide to position denture teeth. This method suggested would result in a better buccolingual positioning of the posterior teeth, which would help avoid encroaching on the tongue space, thereby improving phonetics and speech with dentures.

Clinical significance: ICW bears a relationship with the IDWs in the maxillary and mandibular arches. ICW being a fairly constant anatomical landmark can be used as an additional guide aid in positioning the artificial teeth.

Keywords: Denture teeth positioning, intercanine width, intercondylar width, intermolar width.

The Journal of Contemporary Dental Practice (2021): 10.5005/jp-journals-10024-3199
\end{abstract}

\section{INTRODUCTION}

Esthetic appearance is most often one of the common concerns of a patient who seeks prosthodontic rehabilitation. Achieving acceptable esthetics and functionality while rehabilitation of missing natural teeth is often posed as a challenge. The arrangement of artificial teeth for complete dentures may appear to some experienced dentists and dental technicians as a straightforward procedure. ${ }^{1}$ It is a challenge to accurately position the artificial teeth in a complete denture prosthesis for a patient who has lost all his natural teeth and does not possess any previous records such as photographs or dental casts.

Clinically, many investigators have recommended the arrangement of artificial teeth to be in a relationship similar to the patient's natural ones or they recommend the use of anatomical landmarks as guides for the correct placement of teeth. ${ }^{1}$ Over the years, norms, criteria, and guidelines for proper tooth selection and arrangements have been suggested by the dental profession. However, the selection and arrangement of teeth for edentulous patients in a natural and aesthetically pleasing form and function have remained a challenging task for most dental professionals. ${ }^{2}$

Many facial measurements like bizygomatic width, intercommissural width, interpupillary width, interalar width, and intercanthal width have been used for the estimation of the width of the maxillary anterior teeth. Yet no single measurement has proved to be completely reliable. ${ }^{3}$ A great number of conducted studies on the human face prove the existence of significant variations in
1,2,5 Department of Prosthodontics and Crown \& Bridge, AB Shetty Memorial Institute of Dental Sciences, NITTE (Deemed to be University), Mangaluru, Karnataka, India

${ }^{3}$ Department of Oral Implantology, AB Shetty Memorial Institute of Dental Sciences, NITTE (Deemed to be University), Mangaluru, Karnataka, India

${ }^{4}$ Department of Prosthodontics and Crown \& Bridge, Dr DY Patil Dental College and Hospital, DY Patil Deemed to be University, Navi Mumbai, Maharashtra, India

${ }^{6}$ Department of Prosthodontics and Crown \& Bridge, Yenepoya Dental College, Yenepoya (Deemed to be University), Mangaluru, Karnataka, India

Corresponding Author: Manoj Shetty, Department of Oral Implantology, AB Shetty Memorial Institute of Dental Sciences, NITTE (Deemed to be University), Mangaluru, Karnataka, India, e-mail: drmanojshetty@nitte.edu.in

How to cite this article: Shetty A, Oswal M, Shetty M, et al. A Study to Determine the Correlation between the Intercondylar and Interdental Widths in South Indian Population: A Cross-sectional Study. J Contemp Dent Pract 2021;22(11):1297-1301.

Source of support: Nil

Conflict of interest: None

parameters among different races, nations, and populations as well as among individuals. ${ }^{4}$ Latta et al. ${ }^{5}$ studied the accuracy of some

(c) The Author(s). 2021 Open Access This article is distributed under the terms of the Creative Commons Attribution 4.0 International License (https://creativecommons. org/licenses/by-nc/4.0/), which permits unrestricted use, distribution, and non-commercial reproduction in any medium, provided you give appropriate credit to the original author(s) and the source, provide a link to the Creative Commons license, and indicate if changes were made. The Creative Commons Public Domain Dedication waiver (http://creativecommons.org/publicdomain/zero/1.0/) applies to the data made available in this article, unless otherwise stated. 
of the most frequently used anatomic landmarks used for denture teeth positioning which included width of the mouth, interalar distance, bizygomatic width, and interpupillary distance. A total of 109 edentulous patients revealed that these measurements varied greatly. The width of the mouth had a range from 36 to $68 \mathrm{~mm}$, interalar width from 29 to $63 \mathrm{~mm}$, bizygomatic width from 125 to $168 \mathrm{~mm}$, and interpupillary distance from 38 to $73 \mathrm{~mm}$. When divided into race and sex, the variation remained statistically significant. They recommended that the use of these landmarks in complete dentures could be questionable.

The fact that incisive papilla is a soft tissue anatomical landmark that has been used frequently for anterior tooth arrangement was described by Mersel and Ehrlich; ${ }^{6}$ Grove and Christensen. ${ }^{7}$ Harper ${ }^{8}$ concluded that the incisal edges of the maxillary central incisors should be set within a range of $5-8 \mathrm{~mm}$ in front of the center of the papilla. Hickey et al., ${ }^{9}$ Martone, ${ }^{10}$ and Murray ${ }^{11}$ suggested this distance to be 8 to $10 \mathrm{~mm}$, whereas Schiffman ${ }^{12}$ related the canines to a line bisecting the papilla. Erlich and Gazit ${ }^{13}$ concluded that the labial surfaces of the maxillary central incisors were at a mean distance of 12-13 $\mathrm{mm}$ anterior to the midpoint of the papilla.

Proper arrangement of teeth and occlusal vertical dimension are the key elements that contribute to the dentofacial esthetics of the edentulous patients. ${ }^{2}$

In the literature, there have been very few studies that assess the relationship of intermolar and intercanine widths and compare the values with intercondylar widths (ICWs). Hence, this study aims to evaluate whether there is a correlation between the ICWs and the interdental widths (IDWs) in the maxillary and mandibular arches in dentate subjects. A constant ratio was then derived, which can be used as an additional guide for the arrangement of denture teeth.

\section{Methodology}

The study was carried out in the Department of Prosthodontics, AB Shetty Memorial Institute of Dental Sciences, Mangaluru. The study began in 2019 and was completed over a period of 2 years. Eighty subjects were included in the study based on $80 \%$ power and $5 \%$ level of significance. Ethical clearance was obtained from the institute's ethical committee and written consent was obtained from each subject. A single trained investigator recorded all the data to avoid any interexaminer bias. For the purpose of the study,

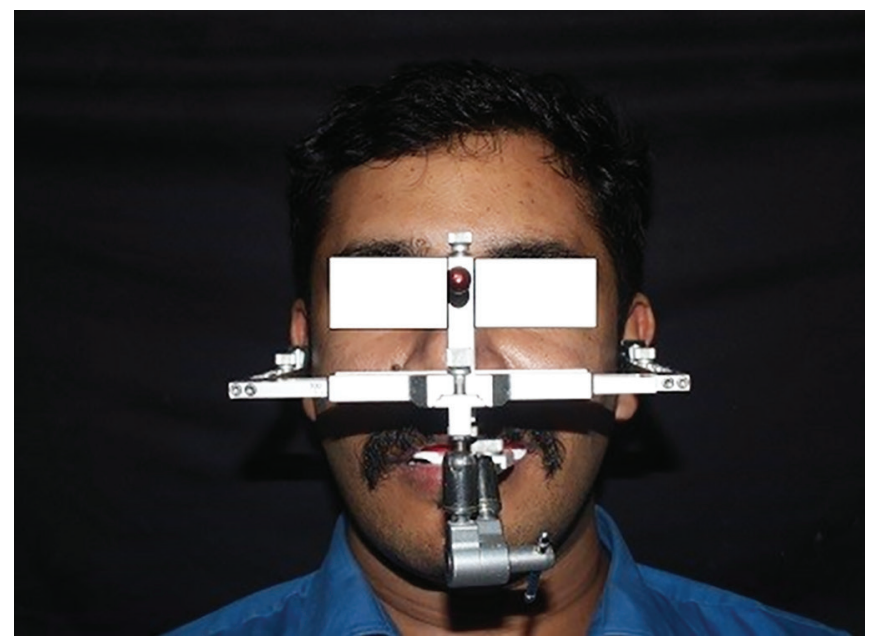

Fig. 1: Measuring the intercondylar distance using an average earpiece facebow subjects belonging to the age groups of $18-45$ years, with full complement of teeth and molar class I relation, were included in the study. The subjects with periodontal disease, subjects with full veneer crowns on canines or molars, subjects who have undergone orthodontic treatment or with supernumerary teeth were excluded from the study. The study first aimed to determine the ratio between ICW and IDW. The ICW was measured using an average earpiece facebow (ARTEX ${ }^{\circledR}$ Gesichtsbogen Facebow). The anterior part of the facebow has a millimeter scale that indicates the intercondylar distance (Figs 1 and 2). Measurements were recorded from the anterior part of facebow. The IDWs were measured directly on the subjects, with a pair of calipers (Figs 3 to 6 ), and recorded as follows:

Upper 3-3 Width (U3-3W) = the distance between the cusp tips of maxillary canines;

Lower 3-3 Width (L3-3W) = the distance between the cusp tips of mandibular canines;

Upper 6-6 Width (U6-6W) = the distance between the mesiobuccal cusp tips of maxillary first molars;

Lower 6-6 Width $($ L6-6W) = the distance between the mesiobuccal cusp tips of mandibular first molars.

A ratio between intercanine width and the intercondylar distance and interfirst molar width and the intercondylar distance was then obtained. Furthermore, a mathematical index was obtained by comparing the mean interdental measurements with the mean intercondylar distance. Following this, a comparison of the estimated IDWs with the actual values measured on the remaining 40 subjects. IDWs were estimated using the mathematical index, following which a comparison of the estimated IDWs with the existing values measured on the rest of the 40 subjects was done.

The data obtained were subjected to statistical analysis using Karl Pearson's correlation test and paired $t$-test.

\section{Results}

At the beginning of the study, 40 subjects were included, of which 20 were males and 20 were females. ICW and IDW were measured in these subjects and the mean was calculated. A ratio was then obtained from the mean ICWs and the mean IDWs.

$$
\text { ICW/U3-3W }=3.31849
$$

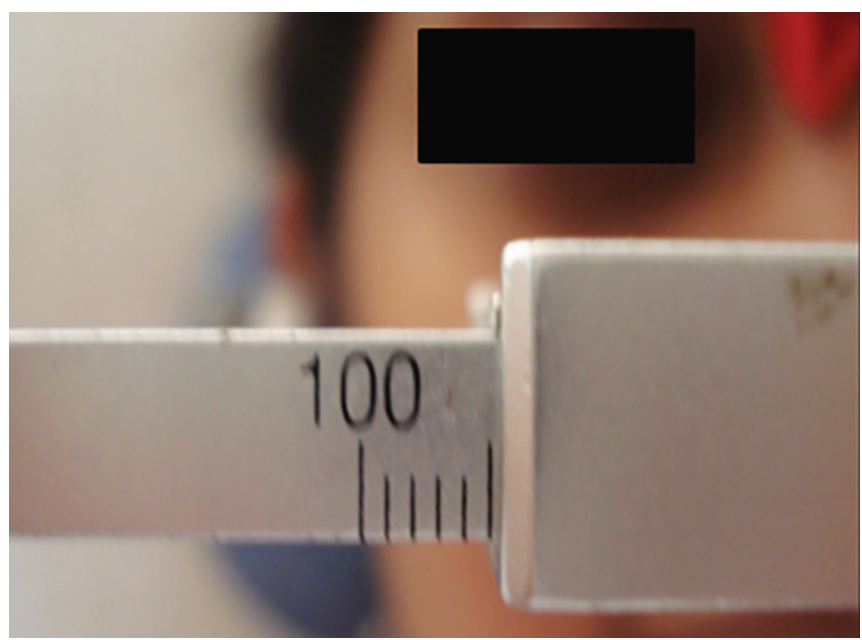

Fig. 2: Millimeter scale on the anterior part of the facebow that indicates the intercondylar distance 


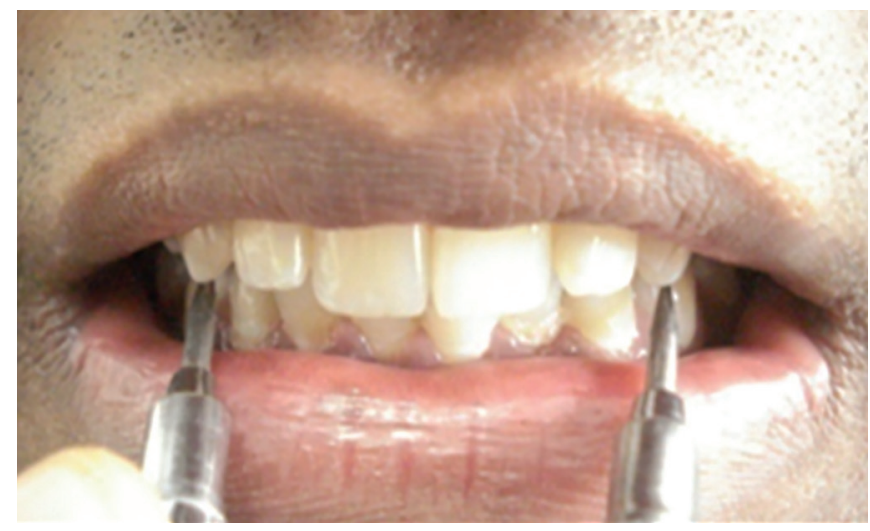

Fig. 3: Measuring the intercanine width in the maxillary arch

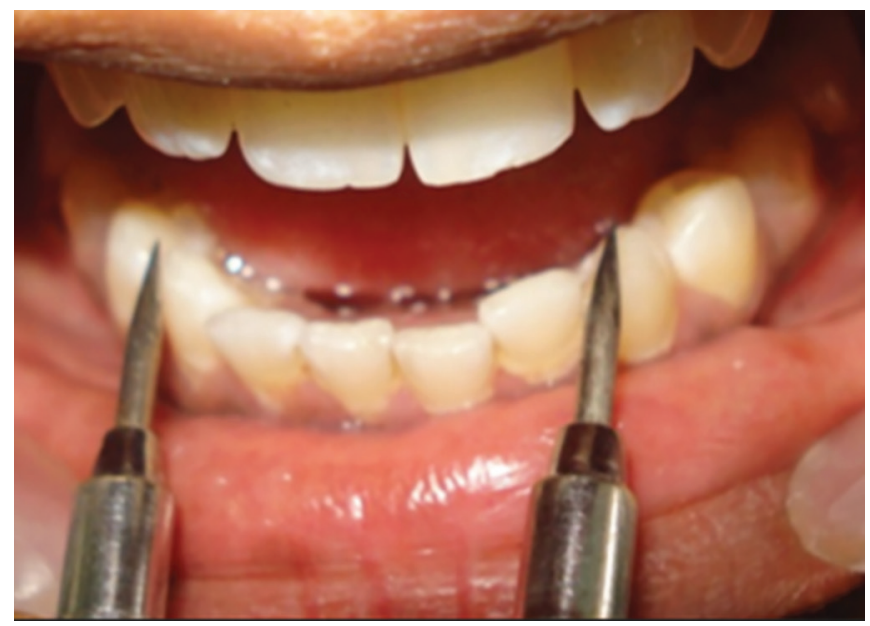

Fig. 5: Measuring the intercanine width in the mandibular arch

ICW/L3-3W $=4.19325$

ICW/U6-6W $=2.37261$

ICW/L6-6W $=2.7227$

These data were subjected to statistical analyses, and it was found to be statistically significant $(p<0.05)$ (Table 1$)$.

Following these measurements, maxillary intercanine distance was found to range between 30.0 and $36.5 \mathrm{~mm}$ with a mean of $34.35 \mathrm{~mm}$. When the mandibular intercanine distance was measured, it ranged from 23.5 to $35 \mathrm{~mm}$, with a mean of $27.18 \mathrm{~mm}$. The maxillary interfirst molar distance was found to range between 34.0 and $55.0 \mathrm{~mm}$, with a mean of $48.21 \mathrm{~mm}$, and the mandibular interfirst molar distance was found to range between 31.5 and $50.0 \mathrm{~mm}$, with a mean of $42.11 \mathrm{~mm}$. The actual and estimated values when compared showed no statistical significance (Table 2). It was found that the mean intercanine width in the maxillary arch (U3-3W) and the mean interfirst molar width in the mandibular arch (L6-6W) were significantly different in males and females ( $p=0.004$ for U3-3W and $p=0.012$ for L6-6W). The mean ICW for both sexes was 114.58 with females having a significantly $(p<0.05)$ shorter ICW $($ mean $=112.05, \mathrm{~s} . \mathrm{d}=5.094)$ than males $($ mean $=117.10$, s.d = 4.706) (Table 3).

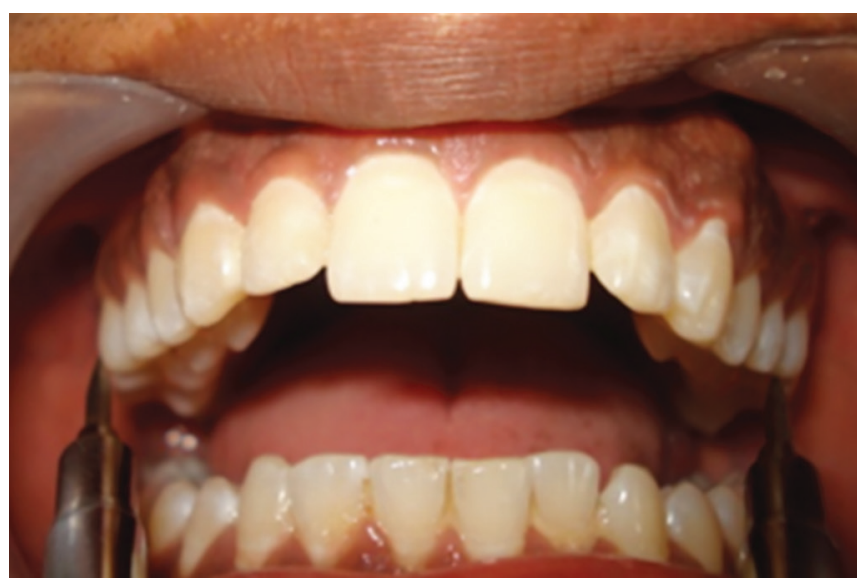

Fig. 4: Measuring the interfirst molar width in the maxillary arch

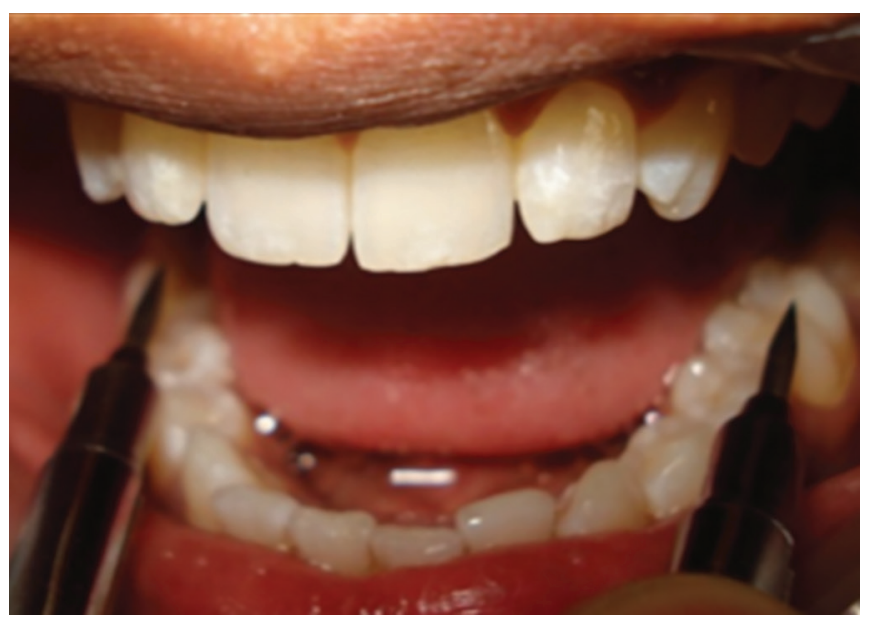

Fig. 6: Measuring the interfirst molar width in the mandibular arch

Table 1: Karl Pearson's correlation between ICWs and IDWs

\begin{tabular}{lccc}
\hline Group & Ratio & Pearson correlation & p value \\
\hline ICW & & & \\
U3-3W & 3.31849 & 0.328 & 0.338 \\
L3-3W & 4.19325 & 0.322 & 0.042 \\
U6-6W & 2.37261 & 0.311 & 0.046 \\
L6-6W & 2.37261 & 0.338 & 0.033 \\
\hline
\end{tabular}

The IDW was correlated to the ICW; the maximal correlation was found to range between ICW and L6-6W ( $p=0.033)$ and the lowest correlation was found to range between ICW and U6-6W ( $p=0.046)$.

\section{Discussion}

Treating edentulism demands restoring the function, esthetics, and comfort of the patient. ${ }^{5}$ One of the factors for successful complete dentures is the correct positioning of the artificial teeth, both anteroposteriorly and mediolaterally, with emphasis on the compensating curves. ${ }^{2}$ Numerous methods are presented in literature for the ideal arrangement of teeth with most of them dependent upon the physical characteristics like the interalar width, bizygomatic width, and facial heights. Besides these intraoral 
Table 2: Paired $t$-test to compare the real and calculated interdental values

\begin{tabular}{|c|c|c|c|c|c|c|c|c|}
\hline & \multirow[b]{2}{*}{$N$} & \multirow[b]{2}{*}{ Mean } & \multirow[b]{2}{*}{ Std deviation } & \multirow[b]{2}{*}{ Mean difference } & \multicolumn{2}{|c|}{$\begin{array}{l}\text { 95\% Confidence interval } \\
\text { for mean }\end{array}$} & \multirow[b]{2}{*}{ t-test value } & \multirow[b]{2}{*}{$p$ value } \\
\hline & & & & & Lower bound & Upper bound & & \\
\hline U3-3W & & & & -0.152 & -1.002 & 0.698 & -0.356 & 0.723 \\
\hline Actual & 40 & 34.43 & 2.101 & & & & & \\
\hline Estimated & 40 & 34.50 & 1.698 & & & & & \\
\hline L3-3W & & & & -0.163 & -1.095 & 0.769 & -0.348 & 0.729 \\
\hline Actual & 40 & 27.41 & 2.640 & & & & & \\
\hline Estimated & 40 & 27.34 & 1.344 & & & & & \\
\hline U6-6W & & & & -0.122 & -1.676 & 1.433 & -0.156 & 0.877 \\
\hline Actual & 40 & 48.57 & 4.325 & & & & & \\
\hline Estimated & 40 & 48.33 & 2.379 & & & & & \\
\hline L6-6W & & & & -0.77 & -1.457 & 1.303 & -0.111 & 0.912 \\
\hline Actual & 40 & 42.08 & 3.864 & & & & & \\
\hline Estimated & 40 & 42.11 & 2.072 & & & & & \\
\hline ICW & & & & 0.050 & -2.412 & 2.512 & 0.040 & 0.958 \\
\hline Actual & 40 & 114.58 & 5.420 & & & & & \\
\hline Estimated & 40 & 114.55 & 5.638 & & & & & \\
\hline
\end{tabular}

Table 3: Paired $t$-test to examine the differences in IDWs and ICWs in males and females

\begin{tabular}{|c|c|c|c|c|c|c|c|}
\hline & \multirow[b]{2}{*}{$N$} & \multirow[b]{2}{*}{ Mean } & \multirow[b]{2}{*}{ Std deviation } & \multicolumn{2}{|c|}{$95 \%$ Confidence interval for mean } & \multirow[b]{2}{*}{$t$-test value } & \multirow[b]{2}{*}{$p$ value } \\
\hline & & & & Lower bound & Upper bound & & \\
\hline \multicolumn{8}{|l|}{ U3-3W } \\
\hline Female & 20 & 33.63 & 2.089 & 33.16 & 34.50 & -2.940 & 0.004 \\
\hline Male & 20 & 35.02 & 1.488 & 34.55 & 35.50 & & \\
\hline Total & 40 & 34.43 & 1.899 & 34.00 & 34.85 & & \\
\hline L3-3W & & & & & & -1.820 & \\
\hline Female & 20 & 26.99 & 2.154 & 26.30 & 27.68 & & 0.073 \\
\hline Male & 20 & 27.83 & 1.960 & 27.20 & 28.45 & & \\
\hline Total & 40 & 27.41 & 2.089 & 26.94 & 27.87 & & \\
\hline \multicolumn{8}{|l|}{ U6-6W } \\
\hline Female & 20 & 47.88 & 3.492 & 46.76 & 49.00 & & 0.062 \\
\hline Male & 20 & 49.26 & 2.723 & 48.39 & 50.13 & & \\
\hline Total & 40 & 48.57 & 3.188 & 47.86 & 49.28 & -1.976 & \\
\hline L6-6W & & & & & & & 0.012 \\
\hline Female & 20 & 41.22 & 3.311 & 40.16 & 42.28 & & \\
\hline Male & 20 & 42.93 & 2.599 & 42.10 & 43.77 & -2.579 & \\
\hline Total & 40 & 42.08 & 3.081 & 41.39 & 42.76 & & \\
\hline \multicolumn{8}{|l|}{ ICW } \\
\hline Female & 20 & 112.06 & 6.094 & 110.42 & 113.68 & -4.606 & 0.000 \\
\hline Male & 20 & 117.10 & 4.706 & 115.60 & 118.60 & & \\
\hline Total & 40 & 114.58 & 5.495 & 113.35 & 115.80 & & \\
\hline
\end{tabular}

landmarks such as incisive papilla, intercanine distance has also been used for selection and arrangement of teeth. ${ }^{14}$ Anatomical landmarks that remain fairly constant throughout the individual's life help determine the position of the teeth closer to that of their predecessors. The present study makes use of the ICW as one such anatomical landmark.

In 1986, Hoffman et al. ${ }^{15}$ evaluated the relation between interalar width and intercanine width on 340 fully dentate subjects. The interalar ratio is most often employed in arranging the teeth, but they found that these two widths did not correlate. The interalar width was 3\% lesser than the intercanine width and 30\% smaller than the intercanine circumferential distance.

LaVere et al. ${ }^{16}$ assessed the length and width of the central incisors in 488 participants and compared the measurements with facial width using the Trubyte tooth indicator. Results of the study suggested that the use of facial as a guide to select the anterior teeth would result in more than $50 \%$ of the teeth selected to be narrower than the natural incisor and $72 \%$ would be longer than the natural teeth present previously.

The maxillary intercanine widths in the previous studies done by Keshvad et al. ${ }^{1}$ and Debnath et al. ${ }^{17}$ have a mean of 33.45 and $34.68 \mathrm{~mm}$, respectively. In the present study, the maxillary intercanine width was found to range between 30.0 and $36.5 \mathrm{~mm}$ with a mean of $34.43 \mathrm{~mm}$, which is in accordance with the abovementioned studies. The mandibular intercanine width in a study done by Keshvad et al. ${ }^{1}$ had a mean of $27.05 \mathrm{~mm}$ which is similar to the mean of $27.21 \mathrm{~mm}$ obtained in our study.

In the studies conducted by Keshvad et al. ${ }^{1}$ and Debnath et al., ${ }^{17}$ the mean intermolar width was 51.56 and $54.78 \mathrm{~mm}$, respectively. The mean intermolar width obtained in our study was 48.57 , which 
is similar to the aforementioned studies. Similarly, the mean value of the mandibular intermolar width in our study was $42.08 \mathrm{~mm}$, which is in accordance with the values of the study carried out by Keshvad et al. ${ }^{1}$

Lazi et al. ${ }^{18}$ measured the intercondylar distance between the centers of condyle in posteroanterior cranial radiographs of the Croatian population. The inter condylar distance (ICD) had the range of $110-145 \mathrm{~mm}$, with the mean of $126 \mathrm{~mm}$. There was a significant difference found between males and females.

In the present study, the IDWs in both maxillary and mandibular arches were correlated to the ICW, where the highest correlation was found to range between ICW and L6-6W and the lowest correlation was found to range between ICW and U6-6W. This is in contrast to the previous studies conducted by Keshvad et al., ${ }^{1}$ Shrestha et al., ${ }^{14}$ and Debnath et al. ${ }^{17}$ which found the highest correlation between ICW and U6-6W. A possible explanation for this is that the study has been conducted on different populations.

Keshvad et al. ${ }^{1}$ and Debnath et al. ${ }^{17}$ in their study obtained the mean intercondylar distance of 110.54 and $109.15 \mathrm{~mm}$, respectively. The mean ICW for both sexes in our study was 114.58 with the female population having an incomparably $(p<0.05)$ shorter ICW than males. This could be explained by the fact that females have a smaller skull size than males.

The results of the study suggest that completely edentulous patients would benefit if a simple measurement could be used to determine the size of their teeth leading to optimal function and esthetics. This method may also guide the laboratory technicians to accurately position the teeth buccolingually, without actually seeing the patient in the chair.

The limitations of this study are that a pair of manual calipers was used to record the intercanine and intermolar widths directly in the oral cavity that could have led to some inaccuracies. A larger sample size could help us achieve a more definitive result.

This method suggested would result in a better buccolingual positioning of the posterior teeth, which would help avoid encroaching on the tongue space, thereby improving phonetics and speech with dentures. However, this is not the only approach to position posterior teeth, but it is an additional guideline, particularly for inexperienced or amateur clinicians while rehabilitating a patient with a complete denture prosthesis.

In the future, studies can be done to assess the difference between the left and right side of the finished dentures and compare using this study method and conventional methods.

\section{Conclusion}

The observations of the present study suggest that during the selection of teeth for complete denture prosthesis, the measurements of the ICW can be used as a guide for the prediction of buccolingual position of teeth in complete dentures.

This would in turn result in a better outcome in terms of comfort, function, and esthetics of the patient.

\section{References}

1. Keshvad A, Winstanley RB, Hooshmand T. Intercondylar width as a guide to setting up complete denture teeth. J Oral Rehabil 2000;27(3):217-226. DOI: 10.1046/j.1365-2842.2000.00509.x.

2. El-Gheriani AS, Davies AL, Winstanley RB. The gothic arch tracing and the upper canine teeth as guides in the positioning of upper posterior teeth. J Oral Rehabil 1989;16(5):481-490. DOI: 10.1111/j.13652842.1989.tb01369.x.

3. Abdullah AM, Stipho HD, Talic YF, et al. The significance of inner canthal distance in prosthodontics. Saudi Dent J 1997;9(1):36-39.

4. Zlataric KD, Kristek E, Celebic A. Analysis of width/length ratios of normal clinical crowns of the maxillary anterior dentition: correlation between dental proportions and facial measurements. Int J Prosthodont 2007;20(3):313-317. PMID: 17580467.

5. Latta Jr GH, Weaver JR, Conkin JE. The relationship between the width of the mouth, interalar width, bizygomatic width, and interpupillary distance in edentulous patients. J Prosthet Dent 1991;65(2):250-254. DOI: 10.1016/0022-3913(91)90170-2.

6. Mersel A, Ehrlich J. Connection between incisive papilla, central incisor and rugae canina. Quintessence Int Dent Dig 1981;12(12): 1327-1329. PMID: 6952297.

7. Grove HF, Christensen LV. Relationship of the maxillary canines to the incisive papilla. J Prosthet Dent 1989;61(1):51-53. DOI: 10.1016/00223913(89)90108-x.

8. Harper RN. The incisive papilla: the basis of a technic to reproduce the positions of key teeth in prosthodontia. J Dent Res 1948;27(6): 661-668. DOI: $10.1177 / 00220345480270060301$.

9. Hickey JC, Boucher CO, Woelfel JB. Responsibility of the dentist in complete dentures. J Prosthet Dent 1962;12(4):637-653. DOI: 10.1016/0022-3913(62)90092-6.

10. Martone AL. Clinical applications of concepts of functional anatomy and speech science to complete denture prosthodontics: Part VIII. The final phases of denture construction. J Prosthet Dent 1963;13(2):204228. DOI: 10.1016/0022-3913(63)90165-3.

11. Murray CG. Anterior tooth positions in prosthodontics. Aust Dent $J$ 1977;22(2):113-119. DOI: 10.1111/j.1834-7819.1977.tb04462.x.

12. Schiffman P. Relation of the maxillary canines to the incisive papilla.J Prosthet Dent 1964;14(3):469-472. DOI: 10.1016/0022-3913(89)90108-x.

13. Ehrlich JA, Gazit ES. Relationship of the maxillary central incisors and canines to the incisive papilla. J Oral Rehabil 1975;2(3):309-312. DOI: 10.1111/j.1365-2842.1975.tb00923.x.

14. Shrestha S, Pandey KK, Verma AK, et al. Comparison of relationship between intercondylar width and maxillary inter-canine width. Int J Res Rep Dent 2019;2(1):1-6.

15. Smith DE. The reliability of pre-extraction records for complete denture. JProsthet Dent 1971;25(6):592-608. DOI: 10.1016/0022-3913(71)90121-1.

16. Hoffman Jr W, Bomberg TJ, Hatch RA. Interalar width as a guide in denture tooth selection. J Prosthet Dent 1986;55(2):219-221. DOI: 10.1016/0022-3913(86)90348-3.

17. LaVere AM, Marcroft KR, Smith RC, et al. Denture tooth selection: an analysis of the natural maxillary central incisor compared to the length and width of the face. Part I. J Prosthet Dent 1992;67(5): 661-663. DOI: 10.1016/0022-3913(92)90166-8.

18. Debnath N, Gupta R, Meenakshi A, et al. Relationship of intercondylar distance with inter-dental distance of maxillary arch and occlusal vertical dimension: a clinical anthropometric study. J Clin Diagn Res: JCDR 2014;8(12):ZC39. DOI: 10.7860/ JCDR/2014/10194.5289. 